\title{
Development of an automated flow-based spectrophotometric immunoassay for continuous detection of zearalenone
}

\author{
Jantra, Jongjit; Zor, Kinga; Sanders, Melanie; De Saeger, Sarah; Hedström, Martin; Mattiasson, Bo
}

Published in:

Biotechnology and Applied Biochemistry

Link to article, DOI:

10.1002/bab.1876

Publication date:

2020

Document Version

Peer reviewed version

Link back to DTU Orbit

Citation (APA):

Jantra, J., Zor, K., Sanders, M., De Saeger, S., Hedström, M., \& Mattiasson, B. (2020). Development of an automated flow-based spectrophotometric immunoassay for continuous detection of zearalenone. Biotechnology and Applied Biochemistry, 67(3), 375-382. https://doi.org/10.1002/bab.1876

\section{General rights}

Copyright and moral rights for the publications made accessible in the public portal are retained by the authors and/or other copyright owners and it is a condition of accessing publications that users recognise and abide by the legal requirements associated with these rights.

- Users may download and print one copy of any publication from the public portal for the purpose of private study or research.

- You may not further distribute the material or use it for any profit-making activity or commercial gain

- You may freely distribute the URL identifying the publication in the public portal 
Development of an Automated Flow-based Spectrophotometric Immunoassay for Continuous

\section{Detection of Zearalenone}

Jongjit Lanfra ${ }^{1,3^{*}}$, Kinga Zór ${ }^{1,4}$, Melanie Sanders ${ }^{5}$, Sarah De Saeger ${ }^{5}$, Martin Hedström ${ }^{1,2}$, and Bo Mattiass

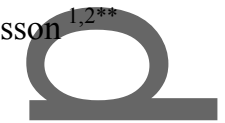

${ }^{1}$ Division of Biotechnology, Lund University, P.O.Box 124, Lund SE-221 00, Sweden

${ }^{2}$ CapSenze Biosystems AB, Scheelevägen 22, Lund SE-223 63, Sweden

${ }^{3}$ King Mongkut's Institute of Technology Ladkrabang, Prince of Chumphon Campus, Pathiu, Chumphon 86160 , Thailand

${ }^{4}$ Center for Intelligent Drug Delivery and Sensing Using Microcontainers and Nanomechanics (IDUN), Department of Health Technology, Technical University of Denmark, 2800 Kgs. Lyngby, Denmark

${ }^{5}$ Center of Excellence in Mycotoxicology and Public Health, Faculty of Pharmaceutical Sciences, Ghent University, Ottergemsesteenweg 460, 9000 Ghent, Belgium

A short running title. An automated flow-ELISA for zearalenone detection.

*Corresponding author: Jongjit Jantra, King Mongkut's Institute of Technology Ladkrabang, Prince of Chumphon Campus, Pathiu, Chumphon 86160, Thailand, E-mail address: jongjit.jan@kmitl.ac.th, Tel. +66 81 9905996.

${ }^{* *}$ Corresponding author: Bo Mattiasson, Division of Biotechnology, Lund University, P.O.Box 124, Lund SE221 00, Sweden, E-mail address: bo.mattiasson@biotek.lu.se
Abstract
Considering the widespread contaminations of food products with mycotoxins, it is important to develop, robust, time- and cost-effective detection methods. We developed and optimized an immunoassay using a continuous flow system for the detection of zearalenone (ZEN). The assay was performed in flow mode This article has been accepted for publication and undergone full peer review but has not been through the copyediting, typesetting, pagination and proofreading process, which may lead to differences between this version and the Version of Record. Please cite this article as doi: 10.1002/bab.1876.
This article is protected by copyright. All rights reserved.

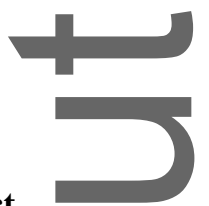


using an automated sequential injection system. Time for an assay cycle was $18 \mathrm{~min}$. Under optimal conditions, the limit for quantification for ZEN was $0.40 \mu \mathrm{g} \mathrm{L}{ }^{-1}$ with a linear dependency between concentration and signal amplitude between 0.10 and $10 \mu \mathrm{g} \mathrm{L}^{-1}$. The assay proved to be robust and reliable with $13 \%$ relative standard deviation (RSD) between measurements. By dissociating the antigen-antibody complex using a regeneration solution, we showed 50 times reusability of the immobilized antibodies without affecting the antigen binding properties.

Keywords: bioanalysis; flow-ELISA; immunoassay; mycotoxin; sequential injection; zearalenone

\section{Introduction}

Zearalenone (ZEN) [6-(hydroxyl-6-oxo-trans-1-undecenyl)-resorcyclic acid lactone] is an estrogenic mycotoxin produced from several species of Fusarium, particularly $F$. graminearum, F. culmorum, F. equiseti and F. verticillioides. Generally, Fusarium fungi grow and invade crops in moist and cool field conditions. ZEN is biosynthesized via a polyketide pathway of a variety of Fusarium species [1]. Toxin production takes place before harvesting but it may also occur post-harvest if the crops are stored under poor conditions. Contamination of ZEN has been found in corn, barley, oats, wheat, sorghum, millet and rice. The toxin has also been detected in cereal products, i.e., flour, malt, soybeans and beer. ZEN is a stable compound and it does not degrade during cooking at high temperature [2]. In animals, this toxin causes embryonic death in a certain stage of gestation, a decrease in fertility and an increase in fetal resorption. ZEN might affect the weight of endocrine glands and also serum hormone levels [2-3]. Recent studies show that there is a potential of ZEN to stimulate the growth of human breast cancer cells [4]. Contamination of foods and feeds by ZEN has been found in many countries in Europe and other continents [5] causing economic losses and lost export opportunities in many countries [6]. Therefore, detection of ZEN in early stage is crucial to reject those toxin-contaminated agricultural products before being used in production of food and feed products.

The maximum limit for ZEN greatly depends on the product type and the end consumer. For instance, in Europe, in the maize intended for direct human consumption, the maximum limit is $200 \mu \mathrm{g} \mathrm{kg}^{-1}$, while in bread (including small bakery wares) the limit was set to $50 \mu \mathrm{g} \mathrm{kg}^{-1}$. In the case of processed cereal-based foods (excluding maize-based foods) and baby foods for infants and young children, the maximum limit is $20 \mu \mathrm{g} \mathrm{kg}$ [7]. Many methods have been developed to evaluate ZEN in agricultural products. The main analytical 
techniques for determination of ZEN include traditional enzyme-linked immunosorbent assay (ELISA) [8-9], gas chromatography-mass spectrometry (GC/MS) [10-11], high-performance liquid chromatography (HPLC) [12-13] and liquid chromatography tandem-mass spectrometry [14-16]. Traditional ELISA is a sensitive method, but in most cases needs to be performed on microtiter plates by skilled personnel. The method is also time-consuming because of extensive pipetting, washing and incubation steps. Chromatographic methods need a large amount of organic solvents and have substantial instrumental operational cost. In addition, the need for detecting ZEN at harvesting site or when the harvest is stored in a silo in order to be able to provide fast results is not met by the above-mentioned methods. None of the above mentioned traditionally used techniques have the potential to be truly portable, automated and at the same time cost efficient, enabling fast on-site detection. Development of detection methods, that could overcome the drawbacks of conventional methods has become a major interest [17-18]. Immunochemically based methods, such as immunoassay, used for first level screening, proved to be suitable for adaptation for on-site detection [19].

Since traditional ELISA cannot be directly applied to a process control on field, the combination of flow injection and traditional ELISA can offer fast, affordable, on-site detection, an approach which has been established by Nilsson et al [20-21] and further developed by others [22-25]. The Versatile Continuous Flow System (VersAFlo) based on sequential flow-injection created by Kumar et al (2012) [24] for bioanalytical application was designed to be reproducible, robust and easy to integrate to an online monitoring system. The automated VersAFlo-system was aimed to minimize errors from human handling, reduce the cost and analysis time. In addition, the system has the potential to be miniaturized and used for on-site, field application. There are several reports on the development of novel immunoassays for detection of ZEN in a static system [26-29] and in a flow system [30-31], however this work is the first report on ZEN detection using a fully automated immunoassay system.

In the VersAFlo-system, the sequential injection mode was operated in combination with sequential competitive binding of free ZEN and ZEN labeled horseradish peroxidase (ZEN-HRP) to the immobilized ZEN antibody in a packed affinity microcolumn. Spectrophotometric detection was performed when 2,2'-azino-bis(3ethyl benzothiazoline)-6-sulfonic acid-diammonium salt (ABTS) got oxidized by HRP and a green-blue product was produced [32]. 


\section{Experimental}

\subsection{Reagents and chemicals}

Zearalenone (ZEN) was purchased from Fermentek (Jerusalem, Israel). Mouse monoclonal antibodies against ZEN (anti-ZEN) and ZEN conjugated with horseradish peroxidase (ZEN-HRP) were produced at Ghent University (Ghent, Belgium) according to Burmistrova et al (2009) [33]. Goat anti-mouse immunoglobulin G (IgG) was purchased from Jackson ImmunoResearch Laboratories Inc (Suffolk, UK). CNBr activated Sepharose 4B was purchased from GE Healthcare (Uppsala, Sweden). Super AquaBlue, the ABTS-based ELISA substrate, a product of eBioscience was from AH diagnostics AB (Solna, Sweden). All chemicals were of analytical grade. Carrier buffer (100 mM phosphate buffer containing $50 \mathrm{mM} \mathrm{NaCl}, \mathrm{pH} 7.4)$ and regeneration buffer (200 $\mathrm{mM}$ glycine-HCl, $\mathrm{pH}$ 2.4) were prepared in ultrapure water from the Milli-Q system from Millipore (Bredford, MA, USA) and filtered using an analytical filter paper from Munktell (Grycksbo, Sweden). All aqueous solutions were also prepared with the same ultrapure water. All the chemicals, if not otherwise specified, were purchased from Sigma-Aldrich (St. Louis, MO, USA).

\subsection{Anti-ZEN immobilization on CNBr-activated Sepharose beads}

The potential benefit of the pre-coated IgG on the anti-ZEN immobilization process was evaluated as described in the supplemental material. Prior to the flow-ELISA study, anti-ZEN was immobilized on $\mathrm{CNBr}$ activated Sepharose 4B beads reconditioned by adding $0.5 \mathrm{~g}$ of dry weight into a sintered glass filter where the beads were suspended and washed in $1.0 \mathrm{mM} \mathrm{HCl}(100 \mathrm{~mL})$ for $15 \mathrm{~min}$. The gel was washed with $50 \mathrm{~mL}$ of coupling buffer $\left(0.2 \mathrm{M} \mathrm{NaHCO}_{3}\right.$ containing $0.5 \mathrm{M} \mathrm{NaCl}, \mathrm{pH}$ 8.3) before removing the supernatant and the gel was kept at $4^{\circ} \mathrm{C}$ until use [24-25]. Anti-ZEN $\left(5.0 \mathrm{mg} \mathrm{L}^{-1}\right)$ in the coupling buffer and the gel were mixed in a centrifuge tube at 1:1 (v/v) ratio. Final concentration of anti-ZEN was calculated to be $2.5 \mathrm{mg} \mathrm{L}^{-1}$. The immobilization took place at $4^{\circ} \mathrm{C}$ for overnight on a rocking table. The unbound antibodies in the supernatant were quantified by protein analysis in order to determine the immobilization yield. The gel was washed once with coupling buffer and the wash-fraction was kept. The remaining active groups on the Sepharose were blocked using $0.1 \mathrm{M}$ Tris- $\mathrm{HCl}, \mathrm{pH} 8.0$ for $2 \mathrm{~h}$ at room temperature. Finally, the gel was washed alternately with $0.1 \mathrm{M}$ acetate buffer ( $\mathrm{pH} 4.0$ ) and $0.1 \mathrm{M}$ Tris- $\mathrm{HCl}$ containing $0.5 \mathrm{M} \mathrm{NaCl}(\mathrm{pH} 8.0)$ for 3 cycles. The Sepharose- 
anti-ZEN was kept in $0.1 \mathrm{M}$ phosphate buffer with $50 \mathrm{mM} \mathrm{NaCl}$ and $0.02 \%(\mathrm{w} / \mathrm{v}) \mathrm{NaN}_{3}, \mathrm{pH} 7.4$ at $4{ }^{\circ} \mathrm{C}$ until use.

The quantification of the unbound protein that was free after the immobilization process was performed based on Bradford assay. A standard curve was constructed using standard bovine serum albumin (BSA). Each of BSA, anti-ZEN, supernatant and wash-fraction $(80 \mu \mathrm{L})$ was separately mixed with $20 \mu \mathrm{L}$ of dye reagent (BioRad, CA, USA) in a microtiter plate. After $5 \mathrm{~min}$, the absorbance was read at $600 \mathrm{~nm}$ (Biotek Instrument, VT, USA). The protein concentration determined in the supernatant and wash-fraction was calculated and referred to the unbound anti-ZEN. Thereafter, the unbound anti-ZEN was subtracted from the initial concentration of antiZEN and the immobilization yield was achieved.

\subsection{Working principle of the VersAFlo-system}

The operation of the VersAFlo-system was achieved by a LabVIEW (National Instruments Co., Austin, TX, USA) based software. The continuous, automated detection was performed based on sequential injection of ZEN, ZEN-HRP and the substrate for the marker-enzyme, using the control software. Fig. 1a shows the architecture of the VersAFlo-system consisting of piston pumps (Pharmacia, Uppsala, Sweden), peristaltic pumps (Watson Marlow, Falmouth, Cornwall, England \& Minipuls 3, Gilson Inc, Middleton, WI, USA), 9-port valves (Pharmacia, Uppsala, Sweden), an affinity microcolumn (15 $\mu \mathrm{L})$ and a spectrophotometer (Lambda Max Model 481, Waters Corporation, Milford, MA, USA). Piston pump-1 was responsible for introducing a carrier buffer throughout the system while piston pump-2 was used for pumping a regeneration buffer. The peristaltic pumps were used for sequential injection of ZEN, ZEN-HRP and substrate via the 9-port valves. The automated sequence of injections, length of the incubation times, washing step were defined by the operator in the LabVIEW software. The operation (time, type of action, flow rate) of each device (pump, valve) was defined as a function of time in the program.

Prior to the assay, the affinity microcolumn was packed with the Sepharose-anti-ZEN and placed in the VersAFlo-system. The carrier buffer (100 mM phosphate buffer containing $50 \mathrm{mM} \mathrm{NaCl}, \mathrm{pH} 7.4)$ was pumped throughout the system $\left(1000 \mu \mathrm{L} \mathrm{min}^{-1}\right)$ for $1 \mathrm{~h}$ to remove anti-ZEN weakly bound to the Sepharose. Each measurement started with an equilibration step using the carrier buffer (1000 $\left.\mu \mathrm{L} \mathrm{min} \mathrm{m}^{-1} / 35 \mathrm{~s}\right)$. Afterwards, the sequence of operation, defined in the LabVIEW software, was performed as presented in Table 1 . When the measurement began, the piston pump-1 was started automatically to deliver the carrier buffer throughout the system. At the same time, the loops $(200 \mu \mathrm{L})$ were filled with ZEN, ZEN-HRP and Super AquaBlue by starting

This article is protected by copyright. All rights reserved. 
of peristaltic pump-1, 2 and 3, respectively. Thereafter, the valves switched to the injection mode and sequential injection was performed with a defined flow rate. The reagents were delivered to the affinity microcolumn where the affinity interaction took place as depicted in Fig. 1b. The first injection of Super AquaBlue was performed to observe the background signal $\left(\mathrm{B}_{\infty}\right)$ and the access reagent was rinsed using the carrier buffer $\left(1000 \mu \mathrm{L} \mathrm{min} \mathrm{m}^{-1}\right.$ 40s). ZEN sample was injected and the immunoreaction with Sepharose-anti-ZEN in the column took place for 240s. As a next step, ZEN-HRP was introduced in the column, where it interacted with free binding sites on the Sepharose-anti-ZEN (240s). The unbound ZEN and ZEN-HRP were washed from the column for $70 \mathrm{~s}\left(1000 \mu \mathrm{L} \mathrm{min}{ }^{-1}\right)$ and Super AquaBlue was injected. A fraction of the substrate was oxidized when passing the affinity microcolumn by HRP in ZEN-HRP. The catalysis resulted in a green-blue product which was quantified by the absorbance at $405 \mathrm{~nm}$. The absorbance was inversely proportional to the concentration of free ZEN in the sample. The piston pump-1 was stopped before the piston pump-2 delivered the regeneration buffer $(200 \mathrm{mM}$ glycine- $\mathrm{HCl}, \mathrm{pH} 2.4)$ right to the affinity microcolumn for 520 seconds. The piston pump-1 was started again to rinse the system and the affinity microcolumn was ready for the next assay.

\subsection{System optimization}

The performance of the flow-ELISA was affected by flow rate and volume of ZEN, ZEN-HRP and Super AquaBlue, therefore, the effect of each parameter was evaluated, by varying one parameter at a time while keeping the other parameters constant. The affinity microcolumn packed with Sepharose-anti-ZEN was connected to the VersAFlo-system and the flow-ELISA was carried out following the flow scheme in Table 1. The duration time was considered based on the dead volumes (the length of tubing from the loop to the microcolumn) to ensure that the reagents were completely pushed to the end of the microcolumn. Initially, the measurement was performed in the absence of free ZEN in order to determine the maximum signal $\left(\mathrm{B}_{0}\right)$. The flow rate of ZEN-HRP was evaluated between 17.5 and $300 \mu \mathrm{L} \mathrm{min}{ }^{-1}$, using volumes between 50 and $300 \mu \mathrm{L}$. Concentration of ZEN-HRP used in the study was $2.2 \mathrm{mg} \mathrm{L}^{-1}$. For Super AquaBlue, flow rates of 188, 375 and

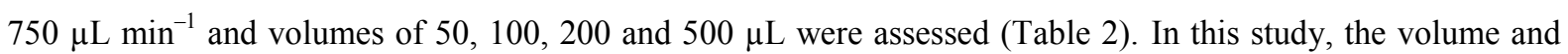
flow rate of the sample (ZEN) and tracer were kept the same $\left(200 \mu \mathrm{L}, 75 \mu \mathrm{L} \mathrm{min}{ }^{-1}\right)$. The efficiency of the regeneration was investigated by varying the volume of regeneration buffer (200 mM glycine- $\mathrm{HCl}, \mathrm{pH} 2.4)$. The flow rate was kept at $1000 \mu \mathrm{L} \mathrm{min}{ }^{-1}$ while the volume of regeneration solution was increased by changing the duration of regeneration up to 650 seconds. The optimal conditions were depicted based on a high response and short analysis time.

This article is protected by copyright. All rights reserved. 


\subsection{Precision}

Between-column repeatability was studied by packing the Sepharose-anti-ZEN in 5 different affinity microcolumns. The maximum signal $\left(\mathrm{B}_{0}\right)$ and background signal $\left(\mathrm{B}_{\infty}\right)$ were determined following the flow scheme in Table 1 . Within-column repeatability studies were carried out by repeating 10 measurements of $\mathrm{B}_{0}$ and $\mathrm{B}_{\infty}$ using the same packed column, with a regeneration step after each measurement. $\mathrm{B}_{\infty}$ was then subtracted from $\mathrm{B}_{0}$. The average response and relative standard deviation (RSD) were calculated.

\section{Results and Discussion}

\subsection{Anti-ZEN immobilization on CNBr-activated Sepharose beads and binding capacity}

In order to determine the immobilization yield, the initial concentration of anti-ZEN and unbound antiZEN were quantified using the Bradford assay. An immobilization yield of $74 \%$ was calculated, with $2.78 \times 10^{-5}$ mg anti-ZEN immobilized in the affinity microcolumn.

The immobilization method was validated by checking the binding capacity between ZEN and Sepharose-anti-ZEN in the sequential injection mode. The preparation of immobilized antibodies was packed in an affinity microcolumn and placed in the VersAFlo system as shown in Fig. 1. The system was operated following the flow scheme in Table 1. Typical responses of the sequential injection flow-ELISA are shown in Fig. 2. $\mathrm{B}_{\infty}$ refers to the background signal when only substrate was injected. The observed small peak was the absorbance of Super AquaBlue at $405 \mathrm{~nm}$. Additionally, the affinity microcolumn was used after the regeneration step. In the assay, the $\mathrm{B}_{\infty}$ was always recorded, and used to evaluate the regeneration efficiency. After regeneration, a small amount of ZEN-HRP, from the previous assay, could still be present in the column and reacted with the substrate, producing the light green product. Therefore, the obtained signal from each concentration of toxin measurement was normalized according to Eq (1). $\mathrm{B}_{\infty}$ indicated background signal when only the substrate was injected. $\mathrm{B}_{0}$ represented the maximum signal obtained when ZEN-HRP and the substrate were injected without free ZEN. B was obtained when free ZEN, ZEN-HRP and the substrate were injected in the system.

$$
\text { Normalized response }=\left[\left(\mathrm{B}-\mathrm{B}_{\infty}\right) /\left(\mathrm{B}_{0}-\mathrm{B}_{\infty}\right)\right] \times 100
$$

Due to the principle of competitive ELISA, the obtained signal was inversely proportional to the concentration of the analyte. In Fig. 2a, it is shown that the maximum signal $\left(\mathrm{B}_{0}\right)$ had the highest response while 
the peak height decrease when $1.5 \mu \mathrm{g} \mathrm{L}^{-1}$ of ZEN was introduced to the system (Fig. 2b), proving that the immobilized anti-ZEN was capable to bind ZEN. Based on the optimization and the results, this immobilization was applied throughout the study.

\subsection{System optimization}

In this work, volume and flow rate of sample (ZEN) and tracer (ZEN-HRP) were operated under the same conditions as defined in Table 2. Flow rate and volume of tracer (ZEN-HRP) and substrate (Super AquaBlue) were then optimized. As expected, by increasing the flow rate of Super AquaBlue and ZEN-HRP, the $\mathrm{B}_{0}$ decreased. However, the variation was very small. When the analysis time was considered, the flow rate of Super AquaBlue and ZEN-HRP was chosen to be 188 and $75 \mu \mathrm{L} \mathrm{min}^{-1}$, respectively (Table 2).

When the flow rate of Super AquaBlue and ZEN-HRP were maintained at the optimum values, the volumes of ZEN-HRP and the substrate were optimized. The $\mathrm{B}_{0}$ increased by increasing the ZEN-HRP volume. Beyond the volume of $200 \mu \mathrm{L}$ the change of $\mathrm{B}_{0}$ was slightly different $(1.50 \pm 0.04$ and $1.7 \pm 0.2)$. Based on these finding, the volume of ZEN-HRP was fixed at $200 \mu \mathrm{L}$. The same trend was observed when the volume of substrate (Super AquaBlue) was varied between 50 and $500 \mu \mathrm{L} . \mathrm{B}_{0}$ increased with increased (50 to $200 \mu \mathrm{L}$ ) substrate volume, and no effect of the signal could be seen beyond the volume of $200 \mu \mathrm{L}(1.46 \pm 0.04$ and $1.4 \pm$ 0.1). The optimum volume of $200 \mu \mathrm{L}$ was selected for the substrate (Table 2).

One of the main advantages of the developed flow-ELISA is the reusability of the affinity microcolumn. When the regeneration step was applied to dissociate the affinity binding between the immobilized antibody and its antigen, the column could be reused several times. To obtain the best performance without damaging the immobilized antibody, the regeneration buffer volume was optimized by changing the regeneration time, in which the buffer interacts with the antibody-antigen complex, between 130 and 650 seconds. $\mathrm{B}_{\infty}$ and $\mathrm{B}_{0}$ were determined as shown in Fig. 3. The absorbance of $\mathrm{B}_{0}$ was relatively stable when changing the regeneration time because the binding capacity of the immobilized anti-ZEN reached the maximum. When there was no regeneration step, $\mathrm{B}_{\infty}$ was $1.28 \pm 0.02$ and gradually decreased from $1.09 \pm 0.05$ to $0.47 \pm 0.01$ with the increased regeneration time which indicated an increase in dissociation of the antibodyantigen complex. Although $\mathrm{B}_{\infty}$ at 520 seconds $(0.58 \pm 0.04)$ was slightly higher than at 650 seconds $(0.47 \pm$ 0.01 ), the optimum regeneration time was selected to be 520 seconds in order to prolong the life time of the column. 
The reusability of the microcolumn was evaluated by measuring the $\mathrm{B}_{0}$ of a fresh packed column for four days, while the column was consecutively used for binding study and regenerated. The $\mathrm{B}_{0}$ of the column was measured before regeneration and after the column was used and regenerated for 13 times after day 1,24 times after day 2, 39 times after day 3 and 53 times after day 4. The regeneration time was 520 seconds as optimum value. The average $\mathrm{B}_{0}$, absorbance at $405 \mathrm{~nm}$, was found to be $1.18 \pm 0.1$, with $9 \%$ relative standard deviation. We also recorded that the $\mathrm{B}_{0}$ decreased with $25 \%$ after the $53^{\text {rd }}$ cycles of regeneration considering $100 \%$ the $\mathrm{B}_{0}$ calculated for the 50 regeneration cycles. The $\mathrm{B}_{0}$ value was the $100 \%$ value of binding by the affinity microcolumn. The sample to be analyzed was always compared to the previous calibration value $\left(\mathrm{B}_{0}\right)$. Therefore, the system compensated for the loss of binding capacity in the affinity microcolumn. From the presented results, the affinity microcolumn can be reused up to 50 times. When the column was not in use, it was kept in the presence of a carrier buffer at $4^{\circ} \mathrm{C}$.

Fig. 4 shows the calibration curve created under the optimum conditions. It was plotted for ZEN concentrations between 0.01 and $50 \mu \mathrm{g} \mathrm{L}^{-1}$. The linear dynamic range was shown between 0.10 and $10 \mu \mathrm{g} \mathrm{\textrm {L } ^ { - 1 }}$ and the calibration equation was $y=-19.01 \ln (x)+62.81$ with an $r$ of 0.998 . The limit of quantification was 0.40 $\mu \mathrm{g} \mathrm{L}^{-1}$, based on $20 \%$ of decrease relative to the maximum signal $(100 \%)$ and the higher limit of detection was $9.5 \mu \mathrm{g} \mathrm{L}^{-1}$, based on $80 \%$ of decrease relative to the maximum signal. The amount of ZEN found in the sample are usually expressed in $\mu \mathrm{g} \mathrm{kg}^{-1}$. The conversion of LOQ $\left(0.40 \mu \mathrm{g} \mathrm{\textrm {L } ^ { - 1 }}\right)$ was performed by comparing the extraction efficiency with the work of Li et al [34]. It can be estimated that the concentration of $0.40 \mu \mathrm{g} \mathrm{L}{ }^{-1}$ is approximately $0.053 \mu \mathrm{g} \mathrm{kg}^{-1}$ of ZEN. Since the lowest maximum limit for ZEN in food products is set at $20 \mu \mathrm{g}$ $\mathrm{kg}^{-1}$ [7], the developed immunoassay could be suitable for ZEN detection in real sample where the dilution is always made because of extraction and matrix interferences.

\subsection{Precision}

It is a crucial to achieve a good repeatability because the final goal of the developed, optimized and fully characterized assay is to be used in the field without extensive optimization and calibration steps. Therefore, between-column repeatability was evaluated. When $15 \mu \mathrm{L}$ of the Sepharose-anti-ZEN was packed in an affinity microcolumn, the average difference between $\mathrm{B}_{0}$ and $\mathrm{B}_{\infty}$ of $1.4 \pm 0.2$ with $12 \% \mathrm{RSD}$ was measured. Within-column repeatability of 10 regeneration cycles was studied. The average of $\mathrm{B}_{0}$ after subtraction from $\mathrm{B}_{\infty}$ was $1.2 \pm 0.2$ with $13 \%$ RSD. The results showed good between and within-column repeatability. As discussed earlier in reusability, the calibration with $\mathrm{B}_{0}$ improves the reliability of the repeated analyses [35]. 


\section{Conclusions}

The continuous flow-ELISA (VersAFlo) based on the sequential injection mode was developed for the detection of ZEN. One assay takes 18 min excluding the regeneration step. It is a rather short analysis time compared to traditional ELISA, which took approximately $5 \mathrm{~h}$ with an overnight step. The flow-ELISA showed a linear range between the observed signal and concentration of ZEN in the sample in the range of 0.10 and $10 \mu \mathrm{g}$ $\mathrm{L}^{-1}$ with the limit of quantification of $0.40 \mu \mathrm{g} \mathrm{L} \mathrm{L}^{-1}$, approximately $0.053 \mu \mathrm{g} \mathrm{kg}^{-1}$. This could be efficient for detection of ZEN in food and feed products. Using complete automation, errors from manual handling can be minimized. Labor-intensive procedures can be eliminated. The system also shows the potential to be miniaturized for a field application.

\section{Author Contributions}

All authors took part in the conceptualization of the study. Material preparation, experimental design, practical work, data collection and analysis were performed by Jongjit Jantra and Kinga Zór. Additionally, Melanie Sanders and Sarah De Saeger contributed with their knowledge about mycotoxin and specially zearalenone. The project was carried out with guidance from Sarah De Saeger, Martin Hedström and Bo Mattiasson. The first draft of the manuscript was written by Jongjit Jantra and all authors worked on the critical revision of the manuscript. All authors read and approved the final manuscript.

\section{Acknowledgements}

This work was supported by the European Union's Seventh Framework Program for research, technological development and demonstration under Grant Agreement Nr: 243633 (Rapid Biosensor for the Detection of Mycotoxin in Wheat, MYCOHUNT). Kinga Zór acknowledges the financial support from the Danish National Research Foundation (DNRF122) and Villum Fonden (Grant No. 9301) for Intelligent Drug Delivery and Sensing Using Microcontainer and Nanomechanics (IDUN). All the experiments and analyses were carried out at the Division of Biotechnology, Lund University, Sweden.

The authors declare that they have no conflict of interest.

\section{References}

1. European Food Safety Authority (2011) EFSA Journal 9, 2197-2319.

2. Kuiper-Goodman, T., Scott, P. M., Watanabe, H. (1987) Regul. Toxicol. Pharmacol. 7, 253-306.

This article is protected by copyright. All rights reserved. 
3. Briones-Reyes, D., Gómez-Martinez, L., Cueva-Rolón, R. (2007) Food Chem. 100, 693-698.

4. Ahamed, S., Foster, J. S., Bukovsky, A., Wimalasena, J. (2001) Mol. Carcinog. 30, 88-98.

5. Zinedine, A., Soriano, J. M., Moltó, J. C., Mañes, J. (2007) Food Chem. Toxicol. 45, 1-18.

6. Rapid Alert System for Food and Feed (2018) https://webgate.ec.europa.eu/rasffwindow/portal/?event=SearchByKeyword\&NewSearch=1\&Keywords=Zearalenone (revise 2018)

7. Commission Regulation (EC) No 1881/2006 of 19 December 2006 (2006). Official Journal of the European Union. 17-18.

8. Warner, R., Ram, B. P., Hart, L. P., Pestka, J. J. (1986) J. Agric. Food Chem. 34, 714-717.

9. Barna-Vetró, I., Gyöngyösi, Á., Solti, L. (1994) Appl. Environ. Microbiol. 60, 729-731.

10. Tanaka, T., Yoneda, A., Inoue, S., Sugiura, Y., Ueno, Y. (2000) J. Chromatogr. A. 882, 23-28.

11. Qian, M., Zhang, H., Wu, L., Jin, N., Wang, J., Jiang, K. (2015) Food Chem. 166, 23-28.

12. Radová, Z., Hajšlová, J., Králová, J., Papoušková, L., Sýkorová, S. (2001) Cereal. Res. Commun. 29, $435-442$.

13. Silva, C. M. G., Vargas, E. A. (2001) Food Addit. Contam. 18, 39-45.

14. Habler, K., Gotthardt, M., Schüler, J., Rychlik, M. (2017) Food Chem. 218, 447-454.

15. Flores-Flores, M. E., González-Peñas, E. (2017) Food Chem. 218, 378-385.

16. Andrade, G. C. R. M., Pimpinato, R. F., Francisco, J. G., Monteiro, S. H., Calori-Dominggues, M. A., Tornisielo, V. L. (2018) LTW-Food Sci. Technol. 95, 240-246.

17. Man, Y., Liang, G., Li, A., Pan, L. (2017) Toxins. 9, 324.

18. Goryacheva, I. Y., De Saeger, S., Eremin, S. A., Van Peteghem, C. (2007) Food Addit. Contam. 10, 1169-1183.

19. Anfossi, L., Giovannoli, C., Baggiani, C. (2016) Curr. Opin. Biotechnol. 37, 120-126.

20. Nilsson, M., Håkanson, H., Mattiasson, B. (1991) Anal. Chim. Acta. 249, 163-168.

21. Mattiasson, B., Nilsson, M., Berdén, P., Håkanson, H. (1990) Trac-Trend Anal Chem. 9, 317-321.

22. Nandakumar, R., Nandakumar, M. P., Mattiasson, B. (1999) Biosens. Bioelectron. 15, 241-247.

23. Badea, M., Micheli, L., Messia, M. C., Candigliota, T., Marconi, E., Mottram, T., Velasco-Garcia, M., Moscone, D., Palleschi, G. (2004) Anal. Chim. Acta. 520, 141-148.

24. Kumar, M., Mazlomi, M. A., Hedström, M., Mattiasson, B. (2012) Sens. Actuators. B. 161, 855-861.

25. Lebogang, L., Jantra, J., Hedström, M., Mattiasson, B. (2017) Sensors. 17, 1639.

26. Li, L., Ren, S., Shao, M., De Saeger, S., Song, S., Yan, L. (2018) Anal. Methods. 10, 4036-4043. 
27. Tang, X., Li, X., Li, P., Zhang, Q., Li, R., Zhang, W., Ding, X., Lei, J., Zhang, Z. (2014) PloS ONE. 9, 1 7.

28. He, Q., Peng, H., Yang, J., Xu, Z., Fan, C., Sun, Y. (2017) Food. Agric. Immunol. 28, 1477-1495.

29. Zhang, X., Eremin, S. A., Wen, K., Yu, X., Li, C., Ke, Y., Jiang, H., Shen, J., Wang, Z. (2017) J. Agric. Food. Chem. 65, 2240-2247.

30. Urraca, J., Benito-Peña, E., Pérez-Conde, C., Moreno-Bondi, M., Pestka, J. (2005) J. Agric. Food. Chem. 53, 3338-3344.

31. Liu, G., Han, Z., Nie, D., Yang, J., Zhao, Z., Zhang, J., Li, H., Liao, Y., Song, S., De Saeger, S., Wu, A. (2012) Food. Control. 27, 200-205.

32. Zór, K., Castellarnau, M., Pascual, D., Pich, S., Plasencia, C., Bardsley, R., Nistor, M. (2011) Biosens. Bioelectron. 26, 4283-4288.

33. Burmistrova, N. A., Goryacheva, I. Y., Basova, E. Y., Franki, A-S., Elewaut, D., Van Beneden, K., Deforce, D., Van Peteghem, C., De Saeger, S. (2009) Anal. Bioanal. Chem. 395, 1301-1308.

34. Li, X., Li, P., Zhang, Q., Li, R., Zhang, W., Zhang, Z., Ding, X., Tang, X. (2013) Biosens. Bioelectron. 49, 426-432.

35. Borrebaeck, C., Börjesson, J., Mattiasson, B. (1978) Clin. Chim. Acta. 86, 267-278. 


\section{Figure caption}

Fig. 1 (a) The VersAFlo-system consisted of two piston pumps, three peristaltic pumps, 9-port valve, an affinity microcolumn and a spectrophotometer. (b) Detection principle of the flow-ELISA taking place in the affinity microcolumn packed with the Sepharose-anti-ZEN. Free ZEN and ZEN-HRP were sequentially injected to the column and bind to the immobilized anti-ZEN. The substrate was introduced and the fraction of the substrate was converted by the HRP resulted in a green-blue product. 
Fig. 2 Typical responses of the flow-ELISA when (a) maximum signal $\left(\mathrm{B}_{0}\right)$ and (b) $1.5 \mu \mathrm{g} \mathrm{L} \mathrm{L}^{-1}$ of ZEN (B) was determined.

(a)

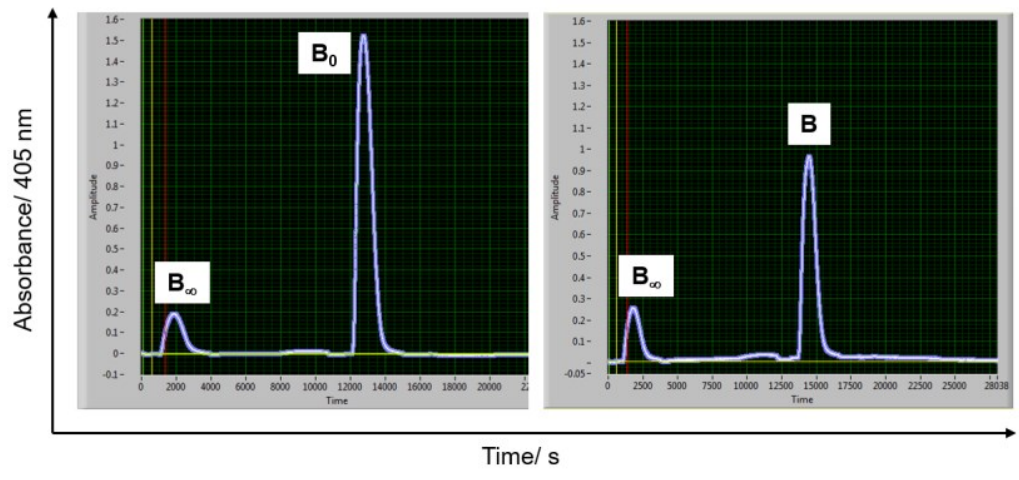

Fig. 3 The absorbance of $\mathrm{B}_{\infty}$ and $\mathrm{B}_{0}$ at different regeneration times ( $130-650$ seconds).

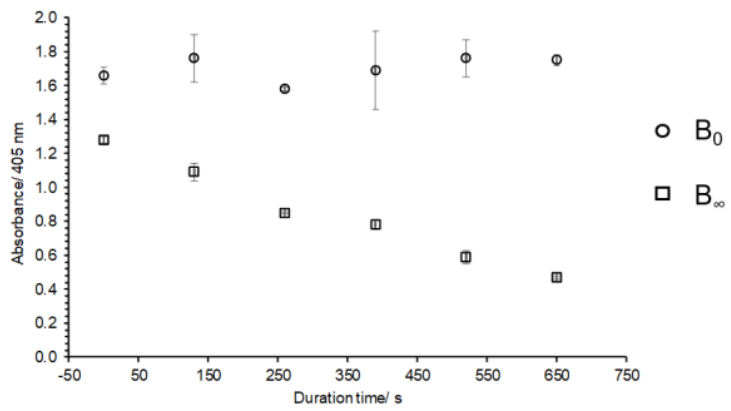


Fig. 4 Calibration curve created under optimum conditions for ZEN concentrations between 0.01 and $50 \mu \mathrm{g} \mathrm{L}{ }^{-1}$.

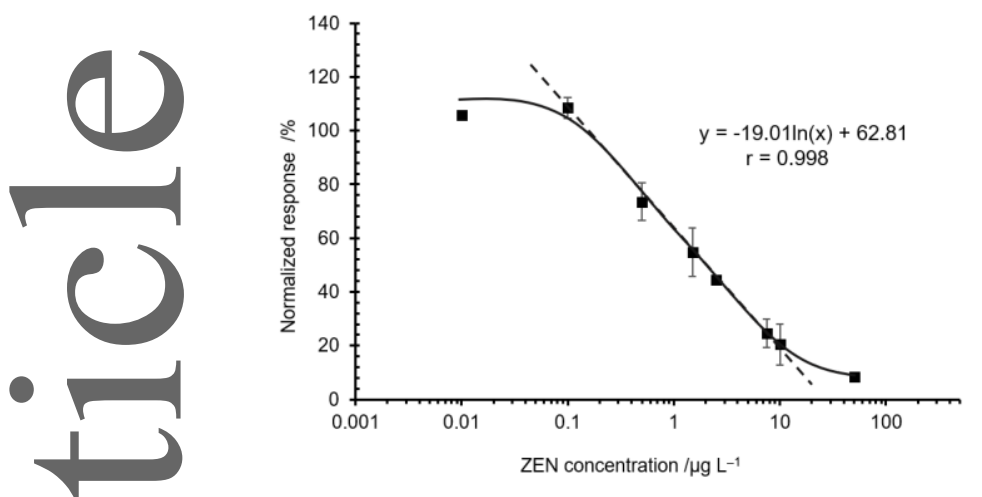

\section{Highlights}

Detection of zearalenone (ZEN) was designed based on an automated flow-injection enzyme-linked immunosorbent assay (ELISA). The immunoreaction of ZEN and ZEN-HRP toward the immobilized anti-ZEN took place in the affinity microcolumn. One assay cycle required only 18 min with the limit of quantification down to $0.40 \mu \mathrm{g} \mathrm{L}^{-1}$. After treatment with a pulse of $200 \mathrm{mM}$ glycine-HCl buffer, $\mathrm{pH} 2.40$, the microcolumn can be reused up to 50 times. 

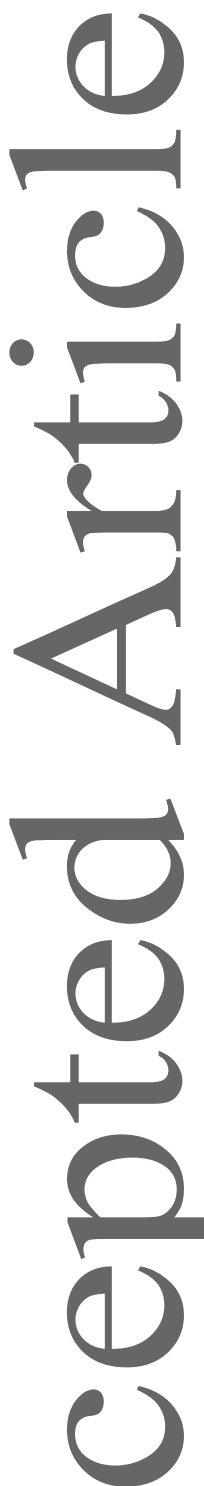

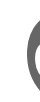

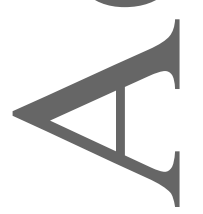

(I) Super AquaBlue

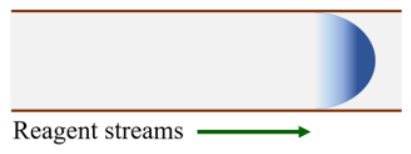

(I) Super AquaBlue

(II) ZEN-HRP है

(III) Super AquaBlue

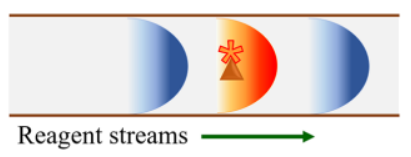

(I) Super AquaBlue

(II) ZEN

(III) ZEN-HRP है?

(IIII) Super AquaBlue

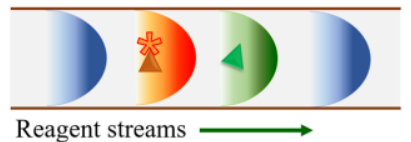

Sepharose-anti-ZEN

Affinity microcolumn
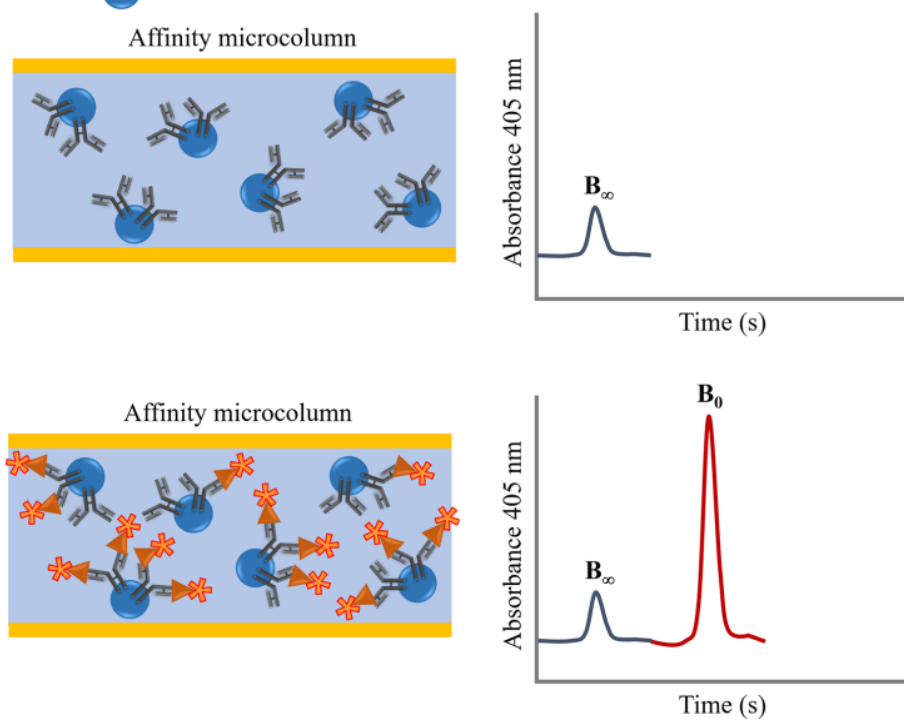

Affinity microcolumn
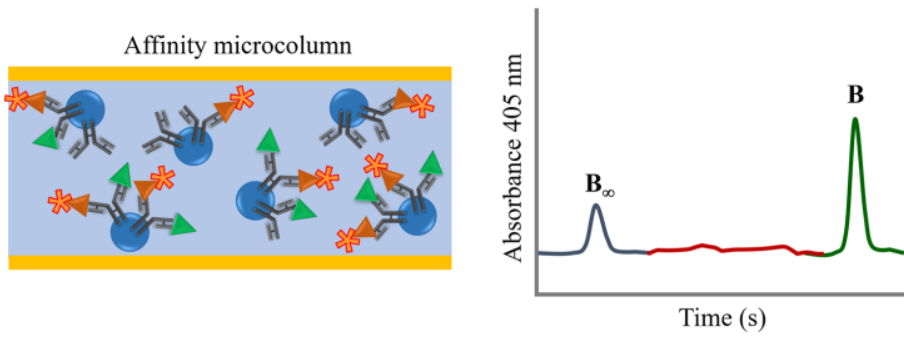

Normalized response $=\left[\left(\mathbf{B}-\mathbf{B}_{\infty}\right) /\left(\mathbf{B}_{0}-\mathbf{B}_{\infty}\right)\right] \times \mathbf{1 0 0}$ 
Table 1 Sequence of reagent injection, flow rate and duration time for ZEN detection using the VersAFlosystem.

Assay phase Carrier flow rate/ $\mu \mathrm{L} \mathrm{min} \mathrm{miran}^{-1} \quad$ Dume/s

\begin{tabular}{lcc}
\hline Equilibration & 1000 & 35 \\
Substrate injection ${ }^{\text {a }}$ & 188 & 240 \\
Rinse & 1000 & 40 \\
Sample injection (free ZEN) & 75 & 240 \\
Tracer injection (ZEN-HRP) & 75 & 240 \\
Rinse & 1000 & 70 \\
Substrate injection & \\
Regeneration & 188 & 240 \\
Rinse & 1000 & 520
\end{tabular}

a. First substrate injection for background determination

b. Second substrate injection to observe the absorbance caused by the enzymatic reaction 
Table 2 Optimization parameters affecting the performance of the VersAFlo-system.

\begin{tabular}{llc}
\hline Parameter & Studied value & Optimum value \\
\hline Flow rate ZEN-HRP $/ \mu \mathrm{L} \mathrm{min}^{-1}$ & $17.5,35,75,150,300$ & 75 \\
\hline Flow rate Super AquaBlue $/ \mu \mathrm{L} \mathrm{min}$ & 188 \\
\hline Volume ZEN-HRP $/ \mu \mathrm{L}$ & $188,375,750$ & 200 \\
\hline Volume Super AquaBlue $/ \mu \mathrm{L}$ & $50,100,200,300$ & 200
\end{tabular}

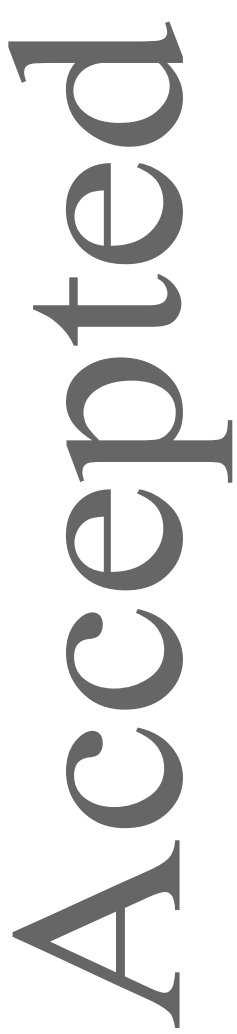

This article is protected by copyright. All rights reserved. 